\title{
Team coaching: Systemic Perspectives and their Limitations
}

\author{
Paul Lawrence \\ Centre for Coaching in Organisations \\ Sydney \\ Australia
}

\begin{abstract}
The terms 'systemic coaching' and 'systemic team coaching' are becoming increasingly prevalent in the team coaching literature. This emphasis on a systemic perspective is almost inevitable given that writers in the broader team development literature have long acknowledged the influence of factors outside the team on events taking place inside the team. Less explicit in the team coaching literature is a more nuanced consideration of what it means to be a systemic team coach with reference to a systems literature that emerged in earnest more than 70 years ago. A detailed exploration of the systems literature not only yields an understanding that multiple systems theories exist, but also that there exists a school of thought that says to think systemically may not always be helpful, that indeed it may limit our understanding of the working of small groups. This paper provides a framework through which the team coach, or aspiring team coach, can reflect not only upon different versions of 'systemic' team coaching, but also the significance of taking a meta-systemic perspective.
\end{abstract}

Key Words: coaching, team coaching, systemic coaching, systems thinking, systemic

\section{Introduction}

Team coaching is still a new discipline, with writers and practitioners still debating how the discipline should be defined and scoped (Wageman \& Lowe, 2019). There exist multiple definitions of team coaching and multiple, but distinct, efforts to conceptually differentiate team coaching from related disciplines, such as facilitation and team building. In the meantime, some authors now seek to differentiate 'team coaching' from 'systemic team coaching'. Hawkins (2011), for example, advocates for the importance of considering the functioning of a team within its broader context and differentiates between team coaching models that explicitly acknowledge the significance of the broader context and those that don't. In many quarters systemic team coaching appears to be being positioned as an advanced form of

This is an Open Access article distributed under the terms of the Creative Commons Attribution (CC BY) License which permits use, distribution and reproduction in any medium, provided the original work is properly cited. 
team coaching. Hawkins (2017), for example, presents a continuum of team coaching, with systemic team coaching positioned as the most developed. However, whilst it is becoming common for authors to talk about systemic team coaching, or systemic approaches to team coaching, the term 'systemic' is not always defined, as will become apparent later in this article. This matters because there exist a multitude of systems theories, representing quite different perspectives as to how organisations-as-systems work.

Hauser (2014) interviewed eight experienced U.S. based coaches, seeking to understand their approach to team coaching. The coaches all emphasised the importance of "helping the team pay attention to, the interrelatedness of the whole system in which the team existed," (p. 59) but these coaches worked differently. One coach (John) focused on relationships between team members, including the team leader. Whilst this approach might be termed systemic, in that it focusses on the functioning of internal relationships, it would not be called systemic by those who use the term to refer to the relationship between a team and other 'sub-systems'. A second coach (Christine) did talk about encouraging the team to pay attention to the needs of their clients, whilst a third coach (Joe) considered the needs of other stakeholders too. So, although all the coaches described their work as systemic, only some attended to connections outside the boundaries of the team, and those that did so considered different aspects of the external environment. Moreover, the study made no mention of the theoretical framework each coach was referring to in describing their work as systemic.

The Hauser study illustrates a confusion reported by many prospective team coaches and clients attempting to understand team coaching and its applications. They face the challenge not only of trying to work out what is team coaching, but also what is systemic team coaching, and how to distinguish between different forms of systemic team coaching. To compound the challenge, there has emerged another view, most clearly articulated by Stacey and Mowles (2016), that says it is not actually useful to compare teams to systems at all.

The aim of this paper is to encourage the team coaching community, including academics and practitioners, to think more broadly about the work that we do and how that work can evolve to become more relevant and effective. The specific objectives of this conceptual paper are to:

- Provide a framework through which the practitioner can examine different versions of 'systemic' team coaching 
- Expound the argument that systemic approaches to team coaching may be useful, but are also limited

- Illustrate how a systemic perspective may even be limiting the progress of team coaching as a discipline

- Suggest a future direction for team coaching that may enhance its applicability and impact

These objectives are achieved by describing five different generic approaches to thinking about systems. Existing team coaching theories are then scrutinised through this framework in an attempt to illustrate how such an exercise enables academics and practitioners to understand and to constructively challenge each other's perspectives. The limitations of a systemic approach are then outlined, before the paper concludes with suggestions as to the future of team coaching.

\section{Systems theories}

There exist hundreds of systems theories, most of which have emerged since the 1950s following the publishing of a spate of papers by biologists, economists and engineers (Stacey \& Mowles, 2016). Three strands of thinking co-evolved (general systems theory, cybernetic systems and systems dynamics), which influenced other disciplines, including management theory. Since the fifties we have seen the emergence of living systems theory (Bailey, 2005; Miller, 1978), autopoiesis (Varela et al. 1974), soft systems methodology (Checkland, 1994, 2000, 2012; Checkland \& Haynes, 1994), critical systems thinking (Ulrich, 2003), chaos theory (Gleick, 1988), complexity theory (Gell Mann, 1994), theories of complex adaptive systems (Marion \& Uhl-Bien, 2001) and more. To fully explore all these theories in detail is beyond the scope of this paper, but various writers have devised useful taxonomies. Building on a taxonomy outlined by Stacey and Mowles (2016), Lawrence $(2019,2021)$ outlines typologies that he references specifically to coaching, including team coaching. Lawrence (2021) describes five categories of systems thinking which are here considered in the contact of team coaching (summarised in table 1).

\section{First-order (linear) systems theories}

Von Bertalanffy (1969) described general systems theory (GST) as a "logico-mathematical science of wholeness". GST is underpinned by three underlying assumptions. First, that a social system is a real system. Second, that the operation of a system is logical and can be mathematically modelled. Third, 
that an external observer can stand outside the system and diagnose its functioning objectively.

A team coach looking through this lens would likely regard the team as an intact system. She would believe it appropriate and useful to position herself aside from the team and objectively diagnose its functioning. The coach would see hierarchy as an important mechanism by which the team operates and would therefore privilege the role of the leader. Comparing the team to a machine, the coach would encourage each component of the machine to direct its efforts toward achieving the objectives of the machine as a whole and ensure that each component performed its role effectively by fulfilling the role officially assigned to it.

\section{First-order (non-linear) systems theories}

Senge (1990) listed five disciplines required of a learning organisation, the fifth of which is 'systems thinking'. The fifth discipline integrates the other four disciplines (personal mastery, mental models, shared vision and team learning). This notion of systems thinking was heavily influenced by 'systems dynamics', a form of systems thinking developed by Forrester and colleagues, also working out of MIT (Senge et al. 1994). In seeking to understand how systems work, the practitioner is advised to watch out for less obvious cause and effect relationships, relationships that are distanced in time and/or space. The practitioner watches out for circles of causality, and the exponential impact of positive feedback. The three underlying assumptions underpinning GST still apply, but the relationship between components of the system are not assumed to be simple or linear.

A team coach looking through this lens would still regard the team as a system. She would still position herself aside from the team and objectively diagnose its functioning and would still see hierarchy as an important mechanism by which the team operates. However, the team coach would also expect to see other factors influencing the functioning of the team and would not expect the relationships between components to be easy to discern. Comparing the team to a machine, the coach would still encourage the team to align around common goals and objectives but would not expect outcomes to be wholly predictable because the 'machine' is so complicated. The coach encourages the team to slow down and reflect on its functioning. 


\section{Second-order systems theories}

Gregory Bateson suggested that people are not able to perceive reality directly, that people can only ever experience a personal representation of reality (Hawkins, 2004; Kobayashi, 1988). With reference to GST, Checkland (2000) suggested that attempts to mathematically model the functioning of all systems has failed because the world is too "complex, problematical and mysterious" (p. 17) for humans to understand. These two narratives suggest that whilst an organisation may function as a system, the essential nature of the system is elusive. This challenges the second assumption underpinning GST, that the operation of a social system can be modelled mathematically. Soft Systems Methodology (SSM) recognised that different people have different perspectives on a situation, and therefore different versions of what needs to happen next. It suggested that people therefore need to come together to build a working model of the system and that they need to learn together from the application of that model (Atkinson \& Checkland, 1988; Checkland, 1994, 2000, 2012; Checkland \& Haynes, 1994). The main difference between first and second order systems thinking is the extent to which it is believed possible to directly discern the functioning of the system. Both approaches nevertheless imply that the leader (or coach) can stand outside the system, alone or with others, and diagnose the working of that system.

A team coach working through this lens would regard the outcome of a team diagnostic as hypothetical. She would encourage team members to share perspectives and to be open to different points of view. She would want to understand perceptions of people outside the team and would encourage the team to be equally curious. This team coach would inevitably be interested in the dynamics of the team, since the extent to which the team is able to understand and integrate the perspectives of others will depend upon the quality of dialogue between team members. This coach is also likely to be more flexible in terms of the scope of the work, being less attached to their own perspective of events, and more curious as to what others think.

\section{Complex Adaptive Systems (CAS)}

Many complexity theories are not dissimilar to first or second order systems thinking. For example, Stacey and Mowles (2016) suggest that chaos theory and theories of dissipative structures (both complexity theories) are similar to first and second order systems thinking in that they focus on the macro and offer little insight as to the detailed functioning of the organisation. Theories of complex adaptive systems (CAS) on the other hand, tend to focus 
on the micro as much as the macro (Boal \& Schultz, 2007; Cavanagh, 2006; Kamo \& Phillips, 1997). Instead of assuming that agents in the system are passive, or that they all behave in a similar fashion, these theories posit that agents in a complex adaptive system operate according to local rules. Local agents interact with each other and from those interactions emerge aggregate behaviours. Local sub-systems are subject to feedback from these aggregated behaviours and respond accordingly. Interaction at the local level therefore continues to evolve as local agents seek to survive in the broader system, and local rules also continue to emerge and evolve (Schneider \& Somers, 2006). This is a fundamentally different perspective on organisation-as-system since it reframes the diagnostic process. Through this lens, the leader of the team (or the coach) cannot meaningfully regard their diagnosis as anything other than the outcome of the functioning of a network of local agents. In other words, the practitioner is deceiving herself if she thinks she can stand outside the team, assess its functioning, then design an intervention based on this 'objective' analysis. The practitioner is an intrinsic component of the system, whether she likes it or not, and whilst her thoughts, behaviours and actions impact on the functioning of the system; so do the thoughts, behaviours and actions of everyone else inside the system (Lawrence, 2021).

A team coach working through this lens recognises that perceptions of team membership, common objectives, team roles, for example, are all in a state of flux, and are constantly emerging and evolving as an outcome of conversations happening both within the team and outside the team. The coach encourages the team to become more aware of the nature of its functioning, and of the impact that conversations outside the team have on conversations taking place inside the team. The team is encouraged to pay attention not only to its internal dynamics, but the dynamics of other sub-systems within the broader system, and how all these different emerging narratives interact. The team is encouraged to understand how goals, objectives and intentions emerge, so that it can develop its capacity to influence those conversations. The team may place great emphasis on the boundaries of the various sub-systems, including its own, as it seeks to understand its functioning in the context of the greater whole.

\section{Meta-systemic thinking}

CAS theories focus on the behaviour of individual agents, and the functioning of sub-systems within the framework of the system as a whole. Mathematical modelers assign rules to individual agents and observe the outcome of the interaction between those agents. But how applicable is this approach in seeking to understand the behaviour of social systems, where the 
component is not a cog or a microchip or an organ of the body, but a human being? Human beings do not act in accordance with standard simple rules. They may be bored by repetition and seek novelty, yet on other days value constancy. They may dislike being told what to do in some contexts and be compliant in others. They may seek change or to avoid change. In this sense human beings, and the interactions between human beings, may be un-modellable, and the system metaphor may not be useful (Bovaird, 2008; Stacey and Mowles, 2016; Suchman, 2011). Stacey and Mowles (2016) critique the living system metaphor on the basis that "organisations are not things at all, let alone living things. They are processes of communication and joint action." (p. 287). An organisation is "an imaginative construct emerging in the relationships between the people who form and are formed by organisation at the same time." The authors suggest that there is no useful analogy between systems and social networks, because to portray the organisation as a system inevitably directs the practitioner to ascribing simple rules to the behaviour of people. Humans don't abide by simple rules. Humans have the capacity to choose actions, often novel actions that cannot be anticipated. Organisations are imaginary constructs; they are not real, which means the boundaries between different parts of the organisation are not real, which implies that teams are not real either; they too are imaginary constructs.

Stacey and Mowles (2016) suggest that instead of thinking about systems, we think in terms of complex responsive processes. From this perspective people interact with each other locally, these local interactions combining to produce population-wide patterns of behaviour. These behaviours do not create boundaries or systems, they just elicit further patterns of interaction. There is no inside or outside of a team or organisation, no meaningful distinction between intra-team dynamics and events taking place outside a notional team boundary. Systemic perspectives, on the other hand, encourage us to think of organisations as machines, or living systems, boundaried from their environments. Suchman (2011) contrasts the value of regarding the organisation as a machine vs regarding the organisation as a collective conversation. The latter metaphor discourages us from thinking about the organisation as a reified object and encourages us to notice self-organising patterns of thinking and relating. Boal and Schultz (2007) suggest that strategic leaders best fulfil their roles through dialogue and storytelling, by which means they are able to shape the evolution of agent interactions and facilitate the emergence of collective shared meanings. Baskin (2008) invites us to substitute the idea of complex adaptive systems for the idea of storied spaces, places where groups of people come to together to negotiate meaning. 
However, Stacey and Mowles do not entirely discount the value of the systems metaphor. To compare organisations to CAS is useful in developing " $a$ clearer understanding of self-organisation and emergence and a strong argument that coherent, population-wide patterns can emerge from many, many local interactions." (p. 325). Lawrence (2021) suggests there are other ways in which the systems metaphor may be useful. Firstly, it helps us to make sense of our dynamic, complex surroundings, and second, it enables us to communicate with others who think through that lens. Whilst organisations are not systems, there may be instances when the metaphor is useful. Or as George E.P. Box expressed it, "All models are wrong, but some are useful." (Box, 1976).

Whilst the systems metaphor might sometimes be helpful, it might also sometimes be unhelpful. The meta-systemic team coach thinks of the 'team' as a social construct. She doesn't expect everyone in the organisation to share a common view as to who is in a particular team or who isn't. Different views are a consequence of different conversations, and those conversations are as likely to include people outside the 'team' and outside the 'organisation' as they are to include team members. This is the main difference, in practice, between the CAS perspective and the meta-systemic perspective. The team coach thinking in terms of CAS may over-privilege the social construct of team, function, organisation and environment. The coach may consequently over-privilege the significance of events happening inside boundaries and under-privilege the significance of relationships with people outside of these boundaries. The coach may over-privilege the team as an entity and fail to recognise that people move in and out of conversation with each other all the time, that definitions of who is in a team and who is not continue to change and evolve, that people have multiple objectives and goals, and that these also continue to change and evolve.

Table 1 summarises the five ways of thinking about systems, the essence of those ideas and their implications for team coaching. In the next section existing team coaching theories are scrutinised through this framework in an attempt to understand the underlying philosophies of these different theories as they relate to systems thinking. 
Table 1: Five ways of thinking systemically and their implications for team coaching

\begin{tabular}{|c|c|c|}
\hline & Thinking & Approach to team coaching \\
\hline First order (linear) & $\begin{array}{l}\text { An organisation is a real system. } \\
\text { The functioning of an organisation is } \\
\text { logical and can be mathematically } \\
\text { modelled. An external observer can } \\
\text { stand outside the system and } \\
\text { diagnose its functioning objectively. }\end{array}$ & $\begin{array}{l}\text { The coach can objectively diagnose the } \\
\text { functioning of a team. She privileges } \\
\text { the role of team leader and encourages } \\
\text { each component of the machine to } \\
\text { direct its efforts toward achieving the } \\
\text { objectives of the machine as a whole. }\end{array}$ \\
\hline First order (non-linear) & $\begin{array}{l}\text { An organisation is a real system, but } \\
\text { the relationships between different } \\
\text { components of the system are less } \\
\text { obvious and sometimes not linear. } \\
\text { Some relationships are distanced in } \\
\text { time and/or space. }\end{array}$ & $\begin{array}{l}\text { The coach does not expect the } \\
\text { relationships between components to be } \\
\text { obvious, nor does she expect the } \\
\text { outcome of interactions between team } \\
\text { members to be predictable. She } \\
\text { encourages the team to slow down and } \\
\text { reflect on its functioning. }\end{array}$ \\
\hline Second order & $\begin{array}{l}\text { The essential nature of the system is } \\
\text { elusive. People need to come } \\
\text { together to build a working } \\
\text { hypothesis of the system and to learn } \\
\text { together from the application of that } \\
\text { hypothesis. }\end{array}$ & $\begin{array}{l}\text { The coach is interested in the dynamics } \\
\text { of the team, since the extent to which } \\
\text { the team is able to understand and } \\
\text { integrate the perspectives of others will } \\
\text { depend upon the team's ability to } \\
\text { engage with itself. }\end{array}$ \\
\hline $\begin{array}{l}\text { Complex adaptive } \\
\text { systemic }\end{array}$ & $\begin{array}{l}\text { Local agents interact with each other } \\
\text { and from those interactions emerge } \\
\text { aggregate behaviours. Interaction at } \\
\text { the local level continues to evolve as } \\
\text { local agents seek to survive in the } \\
\text { broader system. }\end{array}$ & $\begin{array}{l}\text { The coach encourages the team to } \\
\text { become more aware of the nature of its } \\
\text { functioning, and of the impact that } \\
\text { conversations outside the team have on } \\
\text { that functioning. The team is } \\
\text { encouraged to understand how goals, } \\
\text { objectives and intentions emerge. }\end{array}$ \\
\hline Meta-systemic & $\begin{array}{l}\text { Organisations are not things at all, } \\
\text { let alone living things. They are } \\
\text { processes of communication and } \\
\text { joint action. Organisations and } \\
\text { teams are social constructs and } \\
\text { boundaries are not real. }\end{array}$ & $\begin{array}{l}\text { The coach thinks of the 'team' and } \\
\text { boundaries as social constructs. She } \\
\text { sees the team as a part of a broader, } \\
\text { dynamic, social network and is } \\
\text { comfortable working with groups in- } \\
\text { the-moment. }\end{array}$ \\
\hline
\end{tabular}




\section{Team coaching and systemic philosophies}

Relatively few contemporary descriptors of systemic team coaching articulate in detail their underlying philosophy or compare it to other systemic philosophies. A few do. For example:

\section{Thornton}

Thornton (2016) says her book is underpinned by systems theory, specifying chaos and complexity theory. She refers to systems theory rather than systems theories, characterising systems theory in terms of relationships rather than things, on noticing patterns of change rather than static snapshots and seeking to understand subtle links between cause and effect. She advocates the value of regarding organisations as living systems, contrasting this with more mechanistic perspectives. She states that teams are social systems or subsystems and describes the context for coaching in terms of nested systems. The team coach, she says, needs to locate the boundary of the team where it is most usefully drawn. She describes chaos theory in terms of apparently random patterns and refers to the self-organizing characteristic of complex systems. Thornton's rejection of more mechanistic ways of looking at the system suggests that her systems theory is not first order linear. The focus on looking for subtle relationships between cause and effect suggest her theory may be to an extent first order non-linear, whilst acknowledging the team coach has choice in deciding where to locate boundaries sounds second order. She also refers explicitly to aspects of chaos theory and CAS. The categorical assertion that teams are systems seems to rule out the meta-systemic perspective.

\section{Hawkins}

Hawkins (2011) defines systemic team coaching as “... a process by which a team coach works with a whole team, both when they are together and apart, in order to help them improve both their collective performance and how they work together, and also how they develop their collective leadership to more effectively engage with all their key stakeholder groups to jointly transform the wider business." (p. 77). This early articulation of systemic team coaching appears to include elements of first order and/or second order thinking, in that the team coach is counselled not to "become caught up in the team culture or dynamic" (p. 82), advice that implies the team coach is able to stand aside from the dynamics of others in the room and observe events objectively. By contrast Hawkins and Turner (2020) appear to eschew first order thinking in favour of perhaps second order thinking, “... you can never 
know something, let alone somebody, objectively ... your perception of them happens through the lenses of your own rich and sense subjectivity." (p. 22).

Hawkins (2017) description of team coaching appears to reflect a shift toward a CAS perspective in that he writes about the need to focus on the relationship between the team and its environment, a relationship that is dynamic such that the various entities co-evolve. Hawkins (2019) builds on this theme, contrasting 'entity thinking' whereby the coach focuses on the individual, team or organisation, and systemic thinking, in which the coach focuses on the relationships between entities. Hawkins \& Turner (2020) suggest that it is not enough to set goals at the beginning of the process, instead coach and coachee must constantly "discover the work that needs to be done in service of the wider systemic world, informed by regular stakeholder dialogue and engagement." (p. 27). The emphasis on constantly evolving goals, that can only be understood through dialogue with stakeholders, again points to the influence of CAS theory. The authors go on to compare an organisation to a living system and list eight principles of systemic coaching, which include that "We are part of, and affect, all systems we observe and engage with." (p. 29).

The assertion in Hawkins and Turner (2020), that "systems are not things" (p. 21) is less clear, since the authors appear to commend the reader to regard teams as sub-nested systems (p.29). To focus on the relationship between entities rather than the entities themselves, after all, does not preclude the existence of entities. Hawkins (2017) positioning of ecosystemic team coaching as distinct from systemic team coaching is also less clear. Ecosystemic team coaching appears to be different in that it explicitly acknowledges the ecology as well as communities and culture., but this difference appears therefore to be a matter of scope rather than underlying philosophy.

\section{O'Connor and Cavanagh}

In common with Thornton and Hawkins, O'Connor and Cavanagh (2016) depict the organisational system in terms of systems and sub-systems. The smallest system is the cell, followed by the organ, person, dyad, team, corporation, industry, etc. They suggest that the internal dynamics of individuals are not the focal point for team coaching. Rather, team coaching is interested in the conversations between team members insofar as it is important for achieving team goals and the relationship between the team and its wider environment. In exploring the dynamics of team coaching from a systems perspective the authors suggest that fractal patterns can be discerned in 
coaching, similar patterns appearing at different scales of the system, a concept intrinsic to theories of CAS. They write about outcomes that "emerge from the interaction between all these systems levels" (p. 489), again a description that echoes definitions of CAS.

\section{Other authors}

The authors above are, to varying extents, specific as to the philosophy underlying their descriptions of systemic team coaching. Other authors are less explicit. Nevertheless, any theory can be examined in an attempt to understand the underlying systemic philosophy. Hackman and Wageman's (2005) theory of team coaching, for example, would appear to be based largely on first order thinking. They posit that team effectiveness is a function of three processes: i) group effort, ii) the appropriateness of performance strategies and iii) team member knowledge and skill. The authors suggest that approaches focusing on the quality of relationships between team members are less useful, because i) "in some circumstances" performance drives interpersonal relationships rather than the other way around, and ii) there is evidence to suggest that team building activities don't always enhance team performance. Based on studies by Gersick working with project teams (Gersick, 1988, 1989) they also propose that the coach time the nature of their intervention based on where the team is on their journey: beginning, midpoint or endpoint.

Both these propositions appear to be based on a first order, linear way of thinking. The suggestion that team performance is a function of three processes and three processes only, in all contexts, and the selective citing of evidence pointing to the relative ineffectiveness of working with team dynamics, suggest that the authors are looking for a simple and straightforward model by which they can explain team performance. To suggest that coaches decide in advance whether a team is at the beginning of its life, the midpoint or the end, implies that the functioning of all teams can be charted temporally in advance. This again implies underlying assumptions as to the functioning of teams that seems quite linear.

Whittington (2012) refers to the work of Bert Hellinger in describing 'natural orders' or 'organizing principles' that underpin human relationship systems. These organizing forces exist "to sustain a dynamic balance in systems" (p. 16). Systemic coaching "is that which acknowledges, illuminates and releases the system dynamics so each element can function with ease." (p. 35). In the constellation work he describes, clients are encouraged to "face directly into the truths" of the system (p. 14), truths that are difficult to discern. 
This account of the functioning of a system feels second order, in that the author is positing the existence of forces to which people are subject. These forces are described as invisible such that participants in the system can presumably only hypothesise as to the nature of the system.

Table 2 summarises the above analysis. Those authors who explain in some detail what they mean by 'systemic' often reference theories of complex adaptive systems. Other authors appear to be thinking more implicitly in terms of first or second order systems. Less prevalent is a recognition of the limitations of thinking about teams as systems, limitations which will be discussed in the next section.

Table 2: Examples of systemic thinking in the team coaching literature

\begin{tabular}{lll}
\hline Author & Perspective & Dominant way of thinking \\
\hline Thornton (2016) & $\begin{array}{l}\text { References to chaos and complexity theory. } \\
\text { Focussing on the relationships between things and } \\
\text { patterns of change. Seeking to understand subtle } \\
\text { links between cause and effect. The value of } \\
\text { regarding organisations as living systems. }\end{array}$ & Complex adaptive systems \\
& $\begin{array}{l}\text { Focus on the dynamic relationship between } \\
\text { entities. Emphasis on constantly evolving goals, } \\
\text { that can only be understood through dialogue with } \\
\text { stakeholders. Comparison between an organisation } \\
\text { and a living system. }\end{array}$ & Complex adaptive systems \\
$\begin{array}{l}\text { Hawkins (2017, 2019) } \\
\text { (2020) }\end{array}$ & $\begin{array}{l}\text { The organisation as system within a broader } \\
\text { system, comprising smaller sub-systems. } \\
\text { Identification of fractal patterns. Outcomes that } \\
\text { emerge from the interaction between different } \\
\text { levels of system. }\end{array}$ & Complex adaptive systems \\
\hline $\begin{array}{l}\text { O'Connor \& Cavanagher } \\
\text { (2016) }\end{array}$ & $\begin{array}{l}\text { Team effectiveness is a function of three } \\
\text { processes. Depiction of team life as linear } \\
\text { progression. }\end{array}$ & First order \\
\hline $\begin{array}{l}\text { Hackman \& Wageman } \\
\text { (2005) }\end{array}$ & $\begin{array}{l}\text { 'Natural orders' or 'organizing principles' } \\
\text { underpin the functioning of human systems. The } \\
\text { functioning of these natural orders are invisible. }\end{array}$ & \\
\hline Whittington (2012) & & \\
\hline
\end{tabular}




\section{The limitations of systemic approaches}

Systemic approaches imply that the functioning of a team in its context is usefully compared to the functioning of a system, whether that system be a machine, a living system, or some other kind of system. The comparison of a team with a system can be problematic. In this section, two limitations of systemic approaches are discussed. First, the assumption that teams are real, and second the limitations of trying to put boundaries around what we think of as 'team coaching'.

\section{Regarding the team as a real entity}

All contemporary team coaching models appear to discuss the team as a real entity partitioned from its external environment by boundaries. Barley and Kunda (2001) however, suggest that these boundaries are not objectively real; rather they are socially constructed. Mortensen and Haas (2015) suggest that formally assigned boundaries are perceived differently by different people and change constantly over time. Mortensen (2015) report that up to $25 \%$ of a team's membership disagree upon its composition at any point in time. These perspectives suggest that if we are to think in terms of boundaries, we ought to recognise that these boundaries are subjective, impermanent and ever-changing. Hackman and Katz (2010), however, wrote that "Conventional wisdom about group stability is pessimistic about the viability and performance of groups whose members stay together for a long time. Conventional wisdom is wrong." (p. 37). This perspective seems to encourage us not only to think in terms of boundaries, but to regard them as enduring. Wageman and colleagues (2008) list three essential conditions for leadership teams, one of which is that the team is a real team with real boundaries - "everyone knows who is a member and who is not." (p. 16). Through a systemic lens, the idea that team membership is fluid and vague may be problematic.

Wageman and colleagues (2012) recognise that the notion of a traditionally defined team is becoming increasingly outmoded. To address this, they suggest substituting role stability for membership stability, such that the roles within a team are regarded as stable and bounded, even if the people fulfilling those roles come and go. This solution to the issue still requires stability; the emphasis is simply shifted from membership stability to role stability, a shift of focus that does not appear to address the likelihood that team 
roles, like team membership, are subject to the increasingly dynamic nature of the work environment.

Mortensen (2014) accepts that individuals often hold different views to the formally assigned view as to who is in a team and who is not, framing this as a matter of social identity. People can and will shift the extent to which they categorise themselves as belonging to a certain team, depending on the extent to which feeling part of that team serves them well. Tannenbaum and colleagues (2012) noted that teams today operate in more fluid, dynamic and complex environments than before. In the past team boundaries were clear, now teams are much more fluid. There exist temporary flash teams, formed quickly to address a specific need. In response, the authors suggest that organisations help leaders build their teams quickly and build them well. They suggest organisations help team leaders to create the appropriate sense of team identity and that employees are taught 'transportable' teamwork competencies. They suggest that organisations find ways to accelerate team readiness and integration.

Mortensen (2015) invites us to consider four questions, two of which lend themselves to a systemic response, two of which may lead us to regard team coaching through a more meta-systemic lens. His first two questions lend themselves to a systemic response:

- What if we thought of a configuration of multiple boundaries, rather than a single boundary?

- What if we viewed teams as part of a system rather than standalone entities?

Mortensen writes that boundaries are constantly changing and overlapping and are frequently disagreed upon. His first question therefore encourages us to think of boundaries as fluid, contextual and personal, in that different people define boundaries differently. His second question again encourages us to adopt a holistic perspective, so that we define teams clearly in the context of the functioning of the broader system.

A holistic vantage point enables us to notice how team members move from team to team, and that many people are members of more than one team. Much has been written recently about multi-team membership and meta-teams. Mortensen (2015) reports that up to $95 \%$ of people report working in more than one team at once. Multi-team membership is reported to have an adverse impact on the team's focus, its learning, performance and wellbeing over time 
(Margolis, 2020). Nevertheless, multi-team membership is becoming more prevalent because it can lift productivity in the short term and encourage knowledge sharing (Margolis, 2020; Wimmer et al., 2019; O'Leary et al., 2011). The trend toward multi-team membership has resulted in the emergence of the 'meta-team' or 'multiteam system'. Santistevan and Josserand (2019) suggest that organisations in which teams are more fluid might usefully think in terms of an intermediate structure, that they called the meta-team, and cultivate common-mind sets and practices at the meta-team level. Studying specifically multinational organisations, they defined the role of a meta-team as providing a shared sense of reference that members learn through a process of socialisation. Meta-teams enable coordination across the matrix and provide the context and references necessary for members to shift quickly into collaborative behaviours appropriate to the work at hand. Mesmer-Magnus and colleagues (2016) point to the significance of multiple team membership, and the constant moving of members in and out of teams. They suggest a shift of focus to thinking about multiteam systems, a concept similar to that of meta-teams.

These perspectives direct attention to the capacity of members to team quickly with others. Hirschfeld and colleagues (2006) reported that teams whose members have a high level of teamwork knowledge, perform better than teams that don't. In other words, organisations might usefully focus more on the capacity of individuals to team, such that the primary focus of a team coaching assignment will be on what team members are learning generally about teaming. Peters and Carr (2019) suggest that this training needs to be experiential rather than didactic. Mesmer-Magnus and colleagues (2016) also propose that training interventions be targeted at the larger collective and that it is "imperative to look beyond the boundaries of single teams to better clarify how the dynamics across teams underpin team and system effectiveness." ( $\mathrm{p}$. 609). This systemic response to the challenge of multi-teaming may be effective. It still posits however, that at any point in time it is useful and meaningful to define the membership of the specific team, and that it is possible and meaningful to define the boundaries of the meta-team. What we are doing here is retaining the systemic perspective and shifting where we think we can usefully define a boundary that is likely to endure.

Mortensen's (2015) second two questions are:

- What if we defined teams by objectives rather than people?

- What if we considered teams as snapshots in a social process rather than structures? 
These questions may encourage us to think beyond the systems metaphor. A meta-systemic perspective discourages us from thinking about boundaries other than in terms of dynamic social constructs. A team through this lens is the group of people congregated at any point in time to work on an issue together. To talk of a team that exists together for more than a few hours or few days is likely to be problematic in some circumstances, because the nature of the issue on which the group is working is likely to change and evolve, calling for people to join and leave the conversation as appropriate. The problem with a systemic perspective, with its emphasis on boundaries and membership, is that the group in the room may quickly become the wrong group of people to tackle the task at hand. Increasingly, in today's world, people work on multiple tasks simultaneously. In these circumstances, how useful is it to think of a team as a longstanding entity? We may point to research that talks to the value of psychological safety, trust and cohesion, but from a meta-systemic perspective these aspects of a collective are as much a function of the broader social network, and to think of them as characteristics of a boundaried team may inappropriately misdirect the attention of the team coach and the 'team'. The meta-systemic perspective encourages the practitioner to focus on the task at hand, and to be constantly asking the question - 'who needs to be here now?'. The 'team' at any one point in time may be fleeting in its membership, a snapshot in time. It may comprise few or many.

A team coach working through this lens engages with a broad community of people, enabling all those people to engage more effectively in dynamic processes of engaging and disengaging. The role of the leader will be less privileged, a notion supported also by the literature on shared leadership (e.g., Barnett \& Weidenfeller, 2016; Dust \& Zeigert, 2016; Feng et al., 2016; Lorinkova \& Bartol, 2020; Mackie, 2019; Wang et al. 2014). A 'team' would be explicitly recognised as a social construct, a useful label to apply to a group of people in-the-moment. The meta-systemic team coach would place an even stronger emphasis than the systemic team coach on the educational aspect of their role, helping everyone in the broader network develop an enhanced capacity to engage and disengage. The team coach inevitably becomes focused on culture, those factors in the broader environment that encourage people to behave in certain ways in all their interactions.

\section{Regarding team coaching as a real discipline}

A systemic perspective may limit the broader development of the discipline. Many authors believe it is important to demarcate team coaching from other team development interventions, in other words to erect boundaries 
between team coaching and other disciplines. For example, Clutterbuck (2008), Clutterbuck et al. (2019), Hawkins (2011, 2017), Diedrich (2001), Jones and colleagues (2019) all suggest ways in which team coaching can be differentiated from other interventions, such as facilitation, team building, consulting and so on. None of these distinctions are wholly convincing (Lawrence, 2017), not least because they rely on there being single, generally accepted definitions of the disciplines to which team coaching is being compared. Nevertheless, this drive to demarcate persists, in the interests of being able to articulate a simple narrative describing the discipline and how it is distinct and different. This narrative, with its reference to systems and boundaries, may often be useful, particularly from a commercial perspective, helping clients to make sense of something complex. It may also be detrimental, if it limits our thinking, creating barriers between practitioners in different, but related, disciplines. To illustrate the point, we will consider two examples.

Example \#1 - Team coaching and team development.

Appendix 1 presents 16 definitions of team coaching. Whilst these definitions are not all consistent, we can identify some common themes, notably:

- The team coach engages with the entire team (definitions $1,3,9,17$ )

- Team coaching is an iterative process that extends over a long period of time (definitions $2,6,10,16,17$ )

- The purpose of team coaching is to help people align around a common purpose and/or set of objectives (definitions 3, 4, 8, 10, 11, 12, 16)

- A team coach must possess generic coaching skills and have the capacity to work effectively with interpersonal relationships (definitions $5,6,7,8,9,10,13,16)$

The first assumption is highly significant in that it demarcates team coaching quite clearly in terms of scope. If we look at the team development literature more broadly, the reader may become curious as to why team coaching has been defined as an apparent sub-system of a broader system of interventions. In reviewing the last decade of research into team development, Mathieu and colleagues (2019) chart the emergence of input-process-outcome (IPO) frameworks, which preceded the later emergence of input-mediatoroutcome (IMO) models. IPO models describe antecedent factors (inputs) that serve as inputs to team performance, for example individual team member 
characteristics (e.g., competency, personality, values), team-level factors (e.g., task structure, diversity), and organizational and contextual factors (e.g., organizational design, environmental complexity). They describe internal team processes or behaviours, which lead to outcomes, including performance, engagement, satisfaction and wellbeing. IPO models have been superseded by IMO or IMOI models as it has been recognised that many factors linking input and outcome are not behavioural processes, but also emotional states and mental models. It has been noted, however, that IPO frameworks are also quite linear in their depiction of team functioning (Ilgen et al., 2005). In response to criticisms that neither model well represents the dynamic functioning of teams operating in complex environments (Mesmer-Magnus et al., 2016), Mathieu and colleagues (2017) presented a model in which inputs to team functioning, meditating mechanisms and structural factors are depicted as overlapping coevolving facets of teams that combine to generate outcomes. In this model structural features include task scope and complexity, team interdependence and virtuality. Compositional features include average member characteristics, diversity and social fault-lines. Mediating mechanisms include team member behaviours and team 'emergent states', dynamic states that respond to events inside and outside team boundaries (Marks et al., 2001). In Mathieu and colleagues' (2017) model these three categories overlap. Psychological safety, for example, is regarded as both a compositional feature and a mediating mechanism.

If we inspect these models from the broader team literature, we see that contemporary team coaching models address some of these features and not others. Most team coaching models address at least some mediating mechanisms, some address structural features, but very few directly address compositional features. In other words, they do not focus on what happens before the team is formed, the processes through which teams are created and launched, nor do they all have an explicit focus on how the dynamics of membership are paid attention to after the initial creation of a team.

Wageman and Lowe (2019) address this issue explicitly. They cite six design conditions that increase the probability that a team will be successful. These include that the team is a well-composed team, with a sound structure, that is located in a supportive organisational context. They suggest that these design features form the foundations upon which a new team can successfully launch and that these design features are more important than team coaching, as usually defined. The authors suggest that $60 \%$ of a team's effectiveness is attributable to good design, $30 \%$ is due to an effective launch, and $10 \%$ is due to ongoing team coaching. Wageman and Lowe (2019) subsequently 
distinguish between team coaching that supports the work of a team after it has been designed and launched, from team coaching that also includes supporting leaders in designing and launching a team. The authors advocate the second definition as more useful, on the basis that the first form of team coaching is often ineffective.

Peters (2019) also includes team design and team launch as components of her high-performance team coaching system. Including team design in the scope of team coaching means that the coach is likely to spend time working with the team leader, or whoever has the authority to establish the team, before the rest of the team have been identified. This would appear to be contrary to definitions of team coaching that specify that it is team coaching only when the coach is spending time working with the entire team. Accordingly, Murphy and Sayer (2019) in considering an IMOI model state that "Recognised team inputs ... are often already in place and non-negotiable by the time a team coach starts to work with a team. Hence we do not propose to explore inputs too deeply." (p. 81). Hawkins (2017) would appear also to exclude working with the team leader before a team is formed. He suggests that team coaching is "different ... from coaching team leaders on how to lead their teams ..." (p. 78) though he also appears to imply team coaches may have a useful advisory role to play.

In their efforts to demarcate team coaching from other disciplines therefore, some proponents of team coaching may be inadvertently limiting the scope and impact of their work. Team coaches unaware of the extent to which these definitional boundaries may be limiting their impact may find themselves wondering why their efforts don't appear to be more successful. These practitioners may be regarding their own craft through a systemic lens, privileging the contributions of others who profess to be team coaches and aligning with them in efforts to differentiate themselves from others who work with teams. They may be ignoring, or simply be unaware of, relevant wisdoms emerging in conversations taking place in other communities. Accessing the meta-systemic perspective may enable the practitioner to notice the conversations taking place in other communities and to value their relationships with people in those communities as much as much as they do their relationships with other 'team coaches'.

Example \#2 Team coaching and systems thinking.

The broader team development literature is not often explicitly acknowledged in the team coaching literature generally, an odd omission that 
points to the consequence of establishing boundaries in service of reifying a discipline. These boundaries may also limit the extent to which systemic perspectives have become more popular in the team coaching literature. Whilst writers in the team coaching space began writing about the importance of socalled systemic approaches about 15 years ago, and whilst there exists only an occasional team coaching treatise with explicit reference to systems theories, there is a much more substantial consideration of systems in the broader team development literature. McGrath (1997) and McGrath and colleagues (2000) offered theories of groups operating as complex adaptive systems ten years before the theme showed up in the team coaching literature. In critiquing the literature of the time, McGrath and colleagues (2000) point out limitations of that literature, including a tendency to study groups as if they were isolated from their embedding contexts. They recommended that scholars regard groups as complex dynamic systems and that they study groups at the organisational and community level, not just at the group level. By 2005, Ilgen and colleagues noted that most recent theoretical models (DeShon et al., 2004; Kozlowski et al., 1999; Marks et al., 2001; McGrath et al., 2000) all reflected the same underlying philosophy; that teams are complex, dynamic systems, embedded in larger systemic contexts.

Writing about the systems thinking community more than 25 years ago Lane and Jackson (1995) criticised the use of the phrase 'systems thinking':

"The majority of system dynamicists are in the USA and, prompted by Peter Senge's book [The Fifth Discipline] they had started calling their single subject 'systems thinking'. From the European perspective this usage was bewildering, or looked rather arrogant, or just seemed ignorant of the wide range of techniques that shelter beneath the expansive umbrella of that term." (p. 218)

They further warned that:

"Usage of the term 'systems thinking' is spreading in the SD (systems dynamics) community with an enthusiasm which verges on the hegemonic. The employment of this term to describe our own single methodology is virtually to deny the existence of any other, if we use that term for our own discipline, we are putting ourselves in a mental prison."

We might usefully consider these statements with respect to what is happening in the team coaching domain today. Hawkins (2019) suggests that "With the help of many colleagues, I developed Systemic Team Coaching 
between 2000 and 2010. ” (p. 38) Through a meta-systemic lens, even a complex systemic lens, there exist multiple systemic perspectives on team coaching. It is important to be clear therefore, that Hawkins is claiming authorship of a particular systemic perspective. Should we interpret Hawkins' statement otherwise, or indeed the statements of practitioners who do seem to be attempting to define this generic term in their own very specific terms, then we may as a community effectively blind ourselves to the useful perspectives of others. Systemic coaching more broadly, appears to refer to the importance of paying attention to what is happening outside the team in understanding inside the team. This depiction of systemic team coaching as distinct from team coaching is not without its problems, in that it would appear to categorise approaches that emphasise the importance of internal social systems as nonsystemic. O'Connor and Cavanagh (2016), on the other hand, identify three sets of relationships across three systems levels, including patterns of internal dynamics, the relationship between coachee and their immediate context, and the relationship between coachee and the wider systemic environment. To attend solely to internal dynamics is not therefore categorised as being somehow 'non-systemic'.

Rather than focus on what is different about team coaching and attempting to establish a boundaried community with its own unique philosophy, models and frameworks, a meta-systemic perspective may enable a more fluid and inclusive narrative that generates new levels of insight and capability in service of helping organisations become more effective. This may demand that we hold lightly our desire to align around single definitions and clear boundaries. It will require that a desire for clarity and alignment does not get in the way of us being curious as to what others, working within different boundaries, are learning, doing and saying.

\section{Future directions}

As stated in the introduction of this paper, the purpose of this paper is to encourage everyone in the team coaching community to think more broadly about the work that we do and how that work can continue to evolve. The specific objectives of this conceptual paper have been to provide a framework through which the practitioner can examine different versions of 'systemic' team coaching, expound the argument that systemic approaches to team coaching may be both useful and limited, and to suggest a future direction for team coaching that may enhance its applicability and impact. Five different systemic approaches were described, including the meta-systemic approach, that encourages us to hold the metaphor of team-as-system, lightly. Various 
authors depictions of 'systemic' team coaching were scrutinised, an analysis that suggests the emergence of a narrative comparing teams and their environment to complex adaptive systems. The meta-systemic perspective is less prevalent, and it may be through this lens (and others) that team coaching continues to evolve.

How then might a team coach, looking at the world through a metasystemic lens, operate differently to a coach more wedded to a systemic approach? First it should be said that such a coach may in some contexts draw upon some of the same models as the systemic coach. The meta-systemic perspective does not eschew systemic approaches, rather it recognises when the systems metaphor may be useful and when it may not. If a team and its leader have been together for a period of time and expect to be together for another period of time, and if the team and its members are all firmly attached to a more linear way of thinking, then the coach may focus squarely on helping the team define and align around a common purpose and set of objectives. Similarly, a team coach working in a complex environment, where stakeholder perspectives are opaque, dynamic and ever-evolving, in which the organisation is wedded to the idea of the team, the coach may deploy similar models to the complex systemic coach. However, through a meta-systemic perspective, the coach is constantly aware of the limitations of such approaches in some contexts, an awareness that will likely show up in some contracting conversations and in the work with the 'team' itself.

As a number of authors have pointed out recently, traditional approaches to team coaching may feel less relevant these days in some contexts. Team coaches may increasingly experience the need to explore beyond the systemic perspective in their quest to be useful. In many organisations today, people belong to many teams. They flit in and out of teams as feels appropriate, they may gravitate towards those teams whose work and company they enjoy most, and the focus of all these team's work may evolve and change at pace in response to a dynamic and complex external environment. The systemic approach, with its focus on clear boundaries, established membership, and the value of working with a group over time, may not serve so well. In such instances the meta-systemic perspective may enable the team coach to be more agile and flexible. The meta-systemic coach is more likely to consider the following approaches.

First, the meta-systemic perspective encourages the team coach to embark upon a never-ending journey of learning and exploration. In contrast to those practitioners entering the field of team coaching seeking a single model and/or 
discrete knowledge base that will enable them to feel in control from the beginning, the more holistic perspective presents the coach with a formidable body of work to explore and learn, if they are to be most impactful. Even were the coach to restrict their focus to working with intact groups and to decline working on group composition, there exist multiple perspectives on team dynamics; on the mechanisms of conflict, the impact of leadership, learning processes, politics, team efficacy, processes of collaboration and communication, team-member exchange, goal orientation, the dynamics of emerging mental models, the various psychodynamic perspectives, etc... Rather than approach every assignment with the same single model of team functioning, the meta-systemic coach embraces multiple perspectives, including perspectives that may not yet have shown up in the team coaching literature. If the team coach does embrace a broader perspective on team functioning, then she must also become curious about effective team composition. Teams, these days are not always formed in one focused period of time after all. Group composition if often an ongoing task as people constantly come and go. To what extent is the team coach cognisant of the literature around diversity, demography, skill and mindsets, interdependence and virtuality, for example?

Second, the meta-systemic perspective refocuses attention on the importance of contracting. If learning to become a team coach is a never-ending journey of learning and exploration, then for much of a team coach's career there will be many aspects of a team's functioning at which she is not expert. It behooves the team coach therefore to be very clear as to her preferred scope of work at any one time, and to be clear with prospective clients as to her suitability to undertake particular assignments.

Third, the meta-systemic perspective may encourage the team coach to become part of a group. Rather than attempt to manage an assignment independently, the coach may join forces with a group of team coaches, each with their own speciality, but the same underlying meta-systemic philosophy. The team coach is then no longer expected to know everything, but steps in and steps back, just as members of the 'team' may step in and step back, in service of a broader purpose.

Fourth, the meta-systemic perspective encourages the team coach to think more broadly about the social network within which groups are operating. From a purely practical perspective, that may mean focusing at the level of the 'organisation' rather than the level of the 'team'. The coach may invest significant energies in enhancing the capability of people cross an organisation to engage most effectively in groups. An effective process is unlikely to be 
purely didactic, such that the team coach may work with groups of people working on different teams, each group member supporting the others, and/or working with intact 'teams' but with a primary focus on learning.

Finally, the meta-systemic perspective recognises both the value and limitations of working at the organisational level and may spend much of their time working at a more societal level in helping people work together more effectively.

\section{Future research}

In the broader domain of team development, there exists already a substantial body of work exploring the relationship between the performance of teams and multiple variables. This body of research will no doubt continue to develop and evolve. The team coach is more likely to connect and engage with that body of work if they are able to think about their craft and their industry through a meta-systemic lens. If enough team coaches do engage with that body of work then, as the world in becomes more complex and fast moving, we might hope to see future research in the team coaching domain draw upon on early work exploring the functioning of work groups whose membership is more fluid and ambiguous. We can expect to see more research taking place in the field of professional services, for example, where individuals often contribute to the performance of multiple groups, which are constantly forming and reforming in response to changing client needs. We can expect to see more research in industries where different organisations work in collaboration to achieve common goals, in which the people representing those organisations may change in response to the needs of the moment. We can expect to see research further exploring the functioning of teams whose members live in different locations and who may never meet each other face-to-face. We can expect to see the frameworks through which we view the functioning of teams to become less linear, recognising that in many contexts the building and launching of teams will increasingly become more usefully regarded as ongoing tasks rather than activities to negotiate early on in the life of a team. This research is more likely to be collaborative, carried out by people working in team coaching, team development more broadly, systems thinking, and other disciplines whose remits overlap with researchers in the coaching space. As a consequence of all these streams of research we can expect the debate to continue as to how we most usefully define the role of the team coach, or even if it is useful at all to attempt to delineate such a role. 


\section{References}

Anderson, M. C., Anderson, D. L. \& Mayo, W. D. (2008). Team Coaching Helps a Leadership Team Drive Cultural Change at Caterpillar. Global Business and Organizational Excellence, May/June, 40-50

Atkinson, C. J. \& Checkland, P. (1988). Extending the Metaphor "System". Human Relations, 10, 709-725

Bailey, K. (2005). Beyond System Internals: Expanding the Scope of Living Systems. Systems Research and Behavioral Science Systems Research, 22, 497-508

Barley, S. R. \& Kunda, G. (2001). Bringing work back in. Organization Science, 12(1), 76-95

Barnett, R. C. \& Weidenfeller, N.K. (2016). Shared Leadership and Team Performance. Advances in Developing Human Resources, 18(3), 334351

Baskin, K. (2008). Storied Spaces: The human equivalent of complex adaptive systems. Emergence: Complexity and Organization, 10(2), 1-12

Bertalanffy, L. von. (1968). General Systems Theory, George Braziller

Boal, K. \& Schultz, P. L. (2007). Storytelling, Time, and Evolution: The role of strategic leadership in complex adaptive systems. The Leadership Quarterly, 18, 411-428

Bovaird, T. (2008). Emergent Strategic Management and Planning Mechanisms in Complex Adaptive Systems. The Case of the UK Best Value initiative. Public Management Review, 10(3), 319 - 340

Box, G. E. P. (1976). Science and statistics. Journal of the American Statistical Association, 71(356), 791-799,

Britton, J. (2013). From One to Many: Best Practices for Team and Group Coaching, Jossey-Bass

Carr, C., \& Peters, J. (2013). The experience of team coaching: A dual case study. International Coaching Psychology Review, 8(1), 80-98

Cavanagh, M. (2006). Coaching from a Systemic Perspective: A complex adaptive conversation. In: D. R. Stober \& A. M. Grant, (Eds.), Evidence Based Coaching Handbook: Putting best practices to work for your clients, John Wiley \& Sons

Checkland, P. (1994). Systems Theory and Management Thinking. The American Behavioral Scientist, 38(1), 756-791

Checkland, P. (2000). Soft Systems Methodology: A Thirty-Year Retrospective. Systems Research and Behavioral Science, 17, S11-S58

Checkland, P. (2012). Four Conditions for Serious Systems. Systems Research and Behavioral Science, 29, 465-469 
Checkland, P. \& Haynes. M. (1994). Varieties of Systems Thinking: the case of Soft Systems Methodology. Systems Dynamics Review, 2/3, 189-197

Clutterbuck, D. (2007). Coaching the Team at Work, Nicholas Brealey International

Clutterbuck, D. (2008). Coaching the Team. In: D. Drake, D. Brennan \& K. Gortz (Eds.) The Philosophy and Practice of Coaching: Insights and Issues for a New Era, John Wiley \& Sons

Clutterbuck, D. (2009). Coaching teams in the workplace, EFMD Global Focus, 3, 9-14

Clutterbuck, D., Gannon, J., Hayes, S., Iordanou, I., Lowe, K. \& Mackie, D. (2019). Introduction: defining and differentiating team coaching from other forms of team intervention. In: D. Clutterbuck, J. Gannon, S. Hayes, I. Iordanou, K. Lowe \& D. Mackie (Eds.), The Practitioner's Handbook of Team Coaching, Routledge

DeShon, R. P., Kozlowski, S. W. J \& Schmidt, A. M. (2004). A multiple goal, multilevel model of feedback effects on the regulation of individual and team performance in training. Journal of Applied Psychology, 89(6), 1035-1056

DiazGranados, D., Shuffler, M. L., Wingate, J. \& Salas, E. (2017). Team Development Interventions. In: E. Salas, R. Rico \& J. Passmore (Eds.), The Wiley Blackwell Handbook of the Psychology of Team Working and Collaborative Processes, Wiley Blackwell

Diedrich, R.C. (2001). Lessons Learned in — and Guidelines for Coaching Executive Teams. Consulting Psychology Journal: Practice and Research, 53(4), 238-239

Dimas, I., Rebelo, T. M. \& Lourenco, P. (2016). Team coaching: One more clue for fostering team effectiveness. European Review of Applied Psychology, 66(5), 233-242

Dust, S. B. \& Ziegert, J. C. (2016). Multi-Leader Teams in Review: A Contingent-Configuration Perspective of Effectiveness. International Journal of Management Reviews, 18, 518-541

Feng, Y., Hao, B., Iles, P. \& Bown, N. (2016). Rethinking distributed leadership: dimensions, antecedents and team effectiveness. Leadership \& Organization Development Journal, 38(2), 284-302

Gell Mann, M. (1994). Complex Adaptive Systems. In: Complexity: Metaphors, Models and Reality. G. Cowan, D. Pines, D. Meltzer (Eds.), Perseus

Gersick, C. J. G. (1988). Time and transition in work teams: Toward a new model of group development. Academy of Management Journal, 31(1), $9-41$ 
Gersick, C. J. G. (1989). Marking time: Predictable transitions in task groups. Academy of Management Journal, 32(2), 274-309

Gleick, J. (1988). Chaos: The making of the new science, William Heineman

Hackman, J. R. \& Katz, N. (2010). Group behavior and performance. In S. T. Fiske, D. T. Gilbert, \& G. Lindzey (Eds.), Handbook of Social Psychology, John Wiley \& Sons

Hackman, J. R. \& Wageman, R. (2005). A Theory of Team Coaching. The Academy of Management Review, 30(2), 269-287

Hackman, J. R. (1987). The design of work teams. In: J. Lorsch, (Ed.) Handbook of organizational behavior, Prentice-Hall

Hauser, L. L. (2014). Shape-Shifting: A Behavioral Team Coaching Model for Coach Education, Journal of Psychological Issues in Organizational Culture, 5(2), 48-71

Hawkins, P. (2004). A centennial tribute to Gregory Bateson 1904-1980 and his influence on the fields of organizational development and action research. Action Research, 2(4), 409-423

Hawkins, P. (2011). Leadership Team Coaching: Developing Collective Transformational Leadership, Kogan Page

Hawkins, P. (2017). Leadership Team Coaching: Developing Collective Transformational Leadership, $3^{\text {rd }}$ edition, Kogan Page

Hawkins, P. (2019). Systemic Team Coaching. In: D. Clutterbuck, J. Gannon, S. Hayes, I. Iordanou, K. Lowe \& D. Mackie (Eds.), The Practitioner's Handbook of Team Coaching, Routledge

Hawkins, P. \& Smith, N. (2006). Coaching, Mentoring and Organisational Consultancy: Supervision and Development, Open University Press

Hawkins, P. \& Turner. E. (2020). Systemic Coaching. Routledge

Hirschfeld, R. R. T., Jordan, M. H., Feild, H. S., Giles, W. F. \& Achilles, A. (2006). Becoming Team Players: Team Members' Mastery of Teamwork Knowledge as a Predictor of Team Task Proficiency and Observed Teamwork Effectiveness. Journal of Applied Psychology, 91(2), 467-474

Ilgen, J., Hollenbeck, J. R., Johnson, M. \& Jundt, D. (2005). Teams in Organizations: From Input-Process-Output Models to IMOI Models. Annual Review of Psychology, 56, 517-543

Jones, R.J., Napiersky, U. \& Lyubovnikova, J. (2019). Conceptualizing the distinctiveness of team coaching. Journal of Managerial Psychology, 34(2), 62-78

Kamo, J. \& Phillips, F. (1997). The Evolutionary Organization as a Complex Adaptive System. PICMET '97: Proceedings of the Portland 
International Conference on Management of Engineering and Technology

Kobayashi, V. N. (1988). The Self-Reflexive Mind: The Life's Work of Gregory Bateson. Qualitative Studies in Education, 1(4), 347-359

Kozlowski, S. W. J, Gully, S. M., Nason, E. R, Smith, E. M. (1999).

Developing adaptive teams: a theory of compilation and performance across levels and time. In: D. R. Ilgen \& E. D. Pulakos (Eds.), The Changing Nature of Performance, Jossey-Bass

Lane, D. C. \& Jackson, M. C. (1995). Only Connect! An Annotated

Bibliography Reflecting the Breadth and Diversity of Systems Thinking. Systems Research, 12(3), 217-228

Lawrence, P. (2017). What do experienced team coaches do? Current practice in Australia and New Zealand. International Journal of Evidence Based Coaching and Mentoring, 15(1), 95-113

Lawrence, P. (2019) What is Systemic Coaching? Philosophy of Coaching: An International Journal, 4(2), 35-52

Lawrence, P. (2021). Coaching Systemically. Five Ways of Thinking About Systems, Routledge

Lorinkova, N. M. \& Bartol, K. M. (2020). Shared leadership development and team performance: A new look at the dynamics of shared leadership. Personnel Psychology, 1-31

Mackie, D. (2019). Models of shared leadership and team coaching. In: D. Clutterbuck, J. Gannon, S. Hayes, I. Iordanou, K. Lowe \& D. Mackie (Eds.), The Practitioner's Handbook of Team Coaching, Routledge

Margolis, J. (2020). Multiple Team Membership: An Integrative Review. Small Group Research, 51(1), 48-86

Marion, R., \& Uhl-Bien, M. (2001). Leadership in Complex Organizations. The Leadership Quarterly, 12(4), 389-418

Marks, M. A., Mathieu, J. E. \& Zaccaro, S. J. (2001). A temporally based framework and taxonomy of team processes. Academy of Management Review, 26, 356-76

Mathieu, J. E., Gallagher, P. T., Domingo, M. \& Klock, E. A. (2019). Embracing Complexity: Reviewing the Past Decade of Team Effectiveness Research. Annual Review of Organizational Psychology and Organizational Behavior, 6, 17-46

Mathieu J. E., Hollenbeck J. R., Knippenberg D. V., \& Ilgen D. R. (2017). A century of work teams in the journal of applied psychology. Journal of Applied Psychology, 102, 452-467 
McGrath, J. E. (1997). Small group research, that once and future field: An interpretation of the past with an eye to the future. Group Dynamics: Theory, Research, and Practice, 1, 1-27

McGrath, J. E. Arrow, H., \& Berdahl, J. L. (2000). The study of groups: past, present, and future. Personality and Social Psychology Review, 4, 95105

Mesmer-Magnus, J. R., Carter, D. R., Asencio, R. \& DeChurch, L. A. (2016). Space Exploration Illuminates the Next Frontier for Teams Research. Group and Organization Management, 41(5), 595-628

Miller, J.G. (1978). Living Systems, McGraw-Hill

Mortensen, M. (2014). Constructing the team: The antecedents and effects of membership model divergence. Organization Science, 25(3), 909-931

Mortensen, M. (2015). Boundary multiplicity: Rethinking teams and boundedness in the light of today's collaborative environment. INSEAD Working Papers No. 2015/31/OBH. Retrieved from https://papers.ssrn.com/sol3/papers

Mortensen, M., \& Haas, M. R. (2018). Perspective-Rethinking teams: From bounded membership to dynamic participation. Organization Science, 29, 341-355

Murphy, C. \& Sayer, M. (2019). Standing on the shoulders of the science of team effectiveness: building rigour into your team coaching design. In: D. Clutterbuck, J. Gannon, S. Hayes, I. Iordanou, K. Lowe \& D. Mackie (Eds.), The Practitioner's Handbook of Team Coaching, Routledge

O'Connor, S. \& Cavanagh, M. (2016). Group and Team Coaching. In: T. Bachkirova, G. Spence \& D. Drake. The SAGE Handbook of Coaching, SAGE

O’Leary, M. B., Mortensen, M., \& Woolley, A. W. (2011). Multiple team membership: A theoretical model of its effects on productivity and learning for individuals and teams. Academy of Management Review, $36,461-478$

Peters, J. (2019). High performance team coaching: an evidence-based system to enable team effectiveness. In: D. Clutterbuck, J. Gannon, S. Hayes, I. Iordanou, K. Lowe \& D. Mackie (Eds.), The Practitioner's Handbook of Team Coaching, Routledge

Peters, J. \& Carr. C. (2019). What does 'good' look like? An overview of the research on the effectiveness of team coaching. In: D. Clutterbuck, J. Gannon, S. Hayes, I. Iordanou, K. Lowe \& D. Mackie (Eds.), The Practitioner's Handbook of Team Coaching, Routledge

Santistevan, D. \& Josserand, E. (2019). Meta-Teams: Getting Global Work Done in MNEs. Journal of Management, 45(2), 510-539 
Schneider, M. \& Somers, M. (2006). Organizations as complex adaptive systems: Implications of Complexity Theory for leadership research. The Leadership Quarterly, 17, 351-365

Senge, P. (1990). The Fifth Discipline, Random House

Senge, P., Kleiner, A., Roberts, C., Ross., R. \& Smith, B. (1994). The Fifth Discipline Fieldbook, Doubleday

Skiffington, S. \& Zeus, P. (2000). Complete Guide to Coaching at Work, McGraw-Hill

Stacey, R. D. \& Mowles, C. (2016). Strategic Management and Organisational Dynamics, $7^{\text {th }}$ edition, Pearson

Stoffels, D. (2015). A Leader's Framework for Decision Making. Training Journal, June, 50-52

Suchman, A. L. (2011). Organizations as Machines, Organizations as Conversations. Two Core Metaphors and Their Consequences. Medical Care, 49(12), S43-S48

Tannenbaum, S.I., Mathieu, J.E., Salas, E. \& Cohen, D. (2012). Teams Are Changing: Are Research and Practice Evolving Fast Enough? Industrial and Organizational Psychology, 5, 2-24

Thornton, C. (2016). Group and Team Coaching: The secret life of groups, $2^{\text {nd }}$ edition. Routledge

Ulrich, W. (2003). Beyond methodology choice: critical systems thinking as critically systemic discourse. Journal of the Operational Research Society, 54, 325-342

Varela, F. J., Maturana, H. R., \& Uribe, R. B. (1974), Autopoiesis: The Organization of Living Systems, Its Characterization and a Model. Biosystems 5(4), 187-196

Wageman, R., Gardner, H. \& Mortensen, M. (2012). The changing ecology of teams: New directions for teams research. Journal of Organizational Behavior, 33, 301-315

Wageman, R. \& Lowe, K. (2019). Designing, launching, and coaching teams: the 60-30-10 Rule and its implications for team coaching. In: D. Clutterbuck, J. Gannon, S. Hayes, I. Iordanou, K. Lowe \& D. Mackie (Eds.), The Practitioner's Handbook of Team Coaching, Routledge

Wageman, R., Nunes, D. A., Burruss, J. A., \& Hackman, J. R. (2008). Senior leadership teams: What it takes to make them great. Harvard Business School Press

Wang, D., Waldman, D. A. \& Zhang, Z. (2014). A Meta-Analysis of Shared Leadership and Team Effectiveness. Journal of Applied Psychology, 99(2), 181-198

Whittington, J. (2012). Systemic Coaching \& Constellations. Kogan Page 